\title{
Personajes simuladores y simulados, entrelazados en el Quijote
}

\author{
ViCENTE PÉREZ DE LEÓN*
}

Hablar del Quijote desde una perspectiva filosófica es verlo desde alguna Idea, desde algún sistema de Ideas más o menos definido [...]. Lo más probable es que cuando nos referimos al Quijote, lo que interesen sean los sistemas filosóficos que se organizan en torno a la Idea de Hombre [...].

Gustavo Bueno (2005b)

\section{LECTORES, SIMULADORES Y SIMULADOS ENTRELAZADOS EN EL QUIJOTE}

Un reciente estudio cosmológico ha confirmado la posibilidad de que el universo pueda ser una gran simulación ${ }^{1}$. Para probarlo, científicos alemanes han logrado replicar exitosamente un ínfimo fragmento. Una de las conclusiones de este experimento es que si usando la tecnología disponible hoy en día es

* University of Melbourne.

1. Baudrillard (1983: 5) marca la clara diferencia entre disimular y simular, en el sentido de que el primer concepto es parecer que algo no se tiene, mientras que simular consiste en parecer que algo se tiene: «One implies a presence, the other an absence». La simulación puede ser entendida como un acto creativo ya que se alcanza a crear un efecto, una sensación de lo existente. En su estudio sobre el Quijote y el simulacro, Ramírez (2005: 89) defiende la pertinencia de las teorías y principios desarrollados por Baudrillard para explicar la complejidad de los diferentes niveles del significado de la obra cervantina. Más recientemente, Burningham (2008: 54-76, 121-146 y 147-170) ha explorado el concepto de simulación en su estudio comparado del Quijote con películas de cine de Hollywood como Fight Club, Brazil y The Matrix, de la cual llama la atención la pertenencia de los protagonistas al mismo sistema que desean combatir. Del mismo modo, Gasta (2011: 54) llegará a sugerir una lejana inspiración de Einstein en el Quijote en cuanto a su estudio del tiempo cosomológico: "In no way do I wish to suggest that Cervantes's novel can be considered a precursor to Einstein's Theory of General Relativity (1916), though it is quite tempting to think he took inspiration from Cervantes, given that Don Quixote was his second favorite book». 
posible recrear una mínima parte del cosmos, quedan abiertas las puertas para que en un futuro se pueda hacer lo mismo con sectores cada vez mayores, con la esperanza de lograr replicarlo en su conjunto. Como la serpiente Ouróboros, la posibilidad de renovarse eternamente resolvería la cuestión de lo que hubo al inicio, surgiendo entremedias el ser consciente (Hombre en nuestro caso), retroalimentando el proceso y hasta dándole sentido ${ }^{2}$. Asumiendo la finitud del cosmos, la reflexión con la que concluye el artículo sugiere la posibilidad de que lo simulado pueda descubrir a los simuladores:

Nevertheless, assuming that the universe is finite and therefore the resources of potential simulators are finite, then a volume containing a simulation will be finite and a lattice spacing must be non-zero, and therefore in principle there always remains the possibility for the simulated to discover the simulators (Beane, Davoudi y Savage, 2012: 12) ${ }^{3}$.

La idea que ha conducido a la materialización de este experimento no es nueva; ni mucho menos la posibilidad abierta a su conclusión. Utilizando herramientas muy diferentes, tan solo letras e imaginación y partiendo de principios como el del pequeño mundo del hombre ${ }^{4}$, Cervantes, entre otros autores de la modernidad temprana, se adentró en la tarea estética de replicar una pequeña parte del universo tal y como era concebido en su tiempo apoyándose en diversos marcos teórico-artísticos. Uno de los resultados más logrados de este proceso de exploración artística fue el personaje de Don Quijote. No es éste un protagonista cualquiera, sino aquel que por primera vez, en la obra de ficción en la que participa, es capaz de:

a) hacer reflexionar al lector sobre el hecho de que es una creación existente en un entorno cerrado en sí mismo,

b) y elegir autoconscientemente su pertenencia a un sistema abierto a multitud de posibilidades interrelacionadas manifestadas en forma de detalles metaficticios para lograr atraer la atención de seres que dedican su existencia a ser parte de ellas, como son el cura, Sansón Carrasco y los duques.

La autoconsciencia se presenta con pinceladas de trazo fino en la obra, como se pone de manifiesto en las dudas que tiene Don Quijote tras el episodio del barco encantado en la segunda parte, en un lamento sobre la simulación en la que sospecha estar envuelto: «Dios lo remedie; que todo este mundo es máquinas y trazas, contrarias unas de otras. Yo no puedo más» (II, 29)

2. Ver la aplicación de algunos principios de la teoría del universo antrópico en la obra de Cervantes en Pérez de León (2015), siendo el principal de ellos la retroalimentación y adaptación mutual entre realidad y consciencia.

3. El énfasis es mío. Para una profundización sobre las consecuencias filosóficas de la aceptación del universo simulado por el Hombre ver Bostrom (2003).

4. Este asunto está ya presente en Galatea, como ha estudiado Rico (2005: 118-19).

5. En el contexto de la realidad polarizada y contraria a su identidad aludida por Don Quijote, García defiende la inclusión en el análisis de la «consideración teológica» de esta obra cervantina aplicando un método que incluya tanto las «ausencias» como las «presencias» para «someter cada texto cervantino al proceso de evaluación literaria y científica de comprobación y admisión, obser- 


\section{SYMPLOKÉ Y METAFICCIÓN}

La reflexión sobre el modo en el que opera la realidad es siempre un primer paso hacia su comprensión. El Hombre se ha planteado esta cuestión desde sus orígenes, siendo la idea de symploké una de las herramientas más convincentes para su resolución y más recientemente ha sido utilizado como uno de los principios consustanciales al «materialismo filosófico» de Bueno. Según este pensador, el concepto elaborado por Platón ayuda a aproximarse a la realidad mediante una ontología general materialista:

In his Sophist, Plato established the two premises which must be presupposed in every rational process: the first is a principle of connection between some things and others - "if everything were disconnected from everything else, rational discourse would be impossible" - and the second is a principle of disconnection between some things and others - "if everything were connected to everything else, rational discourse would be impossible." Therefore, if we want to rationally approach reality, we must suppose that neither everything is causally connected to everything else, nor is everything disconnected from everything else; that is, we must suppose that things are interwoven (in symploke) with other things, but not with everything (Bueno, 2005a: 47).

Platón propone en El sofista (1992: 251, 255) que una de las dos posibilidades para comprender cómo opera el orden de la realidad nunca es capaz de explicarla en su conjunto: «Si todo estuviese vinculado con todo no podríamos conocer nada». Esta afirmación ha sido utilizada por Bueno para fundamentar su cuestionamiento de aquellos sistemas filosóficos que la utilizan como base para ordenar el sentido de la realidad (Bueno, 1972: 46, 352). A partir de esta afirmación, se puede deducir que la opción de que nada esté exclusivamente relacionado con nada tampoco funciona. Al incluirse al ser humano en esta ecuación, éste aporta también su capacidad de compartir y ser parte de la información esencial, de una materia común con el resto del cosmos,

a) por un lado, al manifestarse su posibilidad de poder compartir un universo eminentemente monista,

b) por otro, al confirmarse su propia existencia como una creación que opera en un limitado entorno eminentemente nihilista.

Por todo lo anterior, una de las claves de la realidad que ordena el universo reside en la posibilidad del ser «simulado» humano de comprender la naturaleza del entrelazamiento de la dualidad que lo rige, nunca completamente monista, ni tampoco totalmente nihilista. Dentro de varias posibilidades, el que el Hombre acepte el rol de ser el elemento que aporta la consciencia necesaria para que el universo exista como tal en su proceso permanente de 
adaptación y viceversa es fundamental. El equilibrio-desequilibrio de nihilismo y monismo está siendo permanentemente creado por la consciencia humana. La esencia necesaria para que la realidad se active, el Hombre, siempre reside en el presente. La información sobre el funcionamiento de la realidad del universo recae en el ser humano, a su vez que en el universo están recónditos todos los secretos que encierra el Hombre, siendo los dos ámbitos regidos por una materia y unas leyes compartidas.

\section{SYMPLOKÉ CERVANTINO: ESTADO DE LA CUESTIÓN}

En este trabajo se utilizará el concepto de la symploké platónica para el estudio de diferentes personajes del Quijote en aras de una mejor comprensión de los factores que conducen tanto a su existencia como a su desaparición en la novela. Maestro ha encontrado en el uso del concepto platónico de la symploké de Bueno una útil herramienta para la interpretación de textos literarios, como explica en su desarrollo de la visión y método de análisis al comentar la cita del Sofista:

Platón describe aquí la estructura enclasada del mundo, que concibe como una estructura trascendental (y no empírica, pero tampoco metafísica). El mundo es una totalidad atributiva, una estructura atributiva, de clases diferentes, cada una de las cuales cumple una función específica dentro del sistema, y porque están relacionadas unas con otras, pero no una con todas, ni todas con todas.

\section{$[\ldots]$}

En consecuencia, como teoría literaria, el materialismo filosófico considera los materiales de la literatura como una totalidad atributiva, cuyas ideas han de interpretarse críticamente siguiendo la disposición combinatoria de una symploké (Maestro, 2006: 86, 89).

Concretamente, la dialéctica de la symploké aplicada a diversos episodios del Quijote se estudia en profundidad en la sección «La dialéctica de Cervantes frente al relativismo de los cervantistas posmodernos» de su obra posterior (Maestro, 2009: 377-456). Por su parte, Hidalgo Tuñón, discípulo de Bueno, también ha utilizado este concepto aplicado específicamente en el Quijote, aduciendo que los protagonistas de la obra combinan diferentes realidades organizadas alrededor de su propia percepción en algunos episodios de la novela. El presente estudio pretende complementar y ampliar las posibilidades de la symploké como método de análisis de la obra cervantina para explicar el sentido de las accciones de personajes cervantinos clave en su desarrollo como entes de ficción autoconscientes, a partir de sus retornos al entrelazamiento primitivo con sus respectivas «muertes públicas», tras su mayor o 
menor aceptación la ley de la symploké que ordena su realidad, como son Grisóstomo y Anselmo o la dualidad Don Quijote-Alonso Quijano.

Tras la exploración de estos planteamientos sobre la necesidad y comprensión de la symploké por parte de la conciencia humana para crear la realidad los delimitaremos al contorno artístico de la obra cumbre cervantina, confirmando que lo propuesto en ella transciende la naturaleza de texto de mero entretenimiento o ejemplaridad. Al estudiar la presencia de las acciones de los protagonistas estudiados en sus entornos monistas y nihilistas se apreciará su interrelación y asimilación a los efectos de la symploké como prueba de su validez como seres verosímiles. Siendo éste el caso, se planteará la posibilidad de que mediante el uso de los recursos literarios de esta obra se sugiera un conocimiento esencial para establecer los límites a la réplica verosímil de la realidad en el ámbito de la ficción 6 .

\section{SIMPLOKÉ PLATÓNICO E I-CHING}

Las posibilidades que ofrece la idea de symploké implica entender la existencia humana como una parte de la realidad, la consciente, unida a la autoconsciencia asociada al rol del ser humano en el cosmos. La busca permanente de la verosimilitud por parte del artista refleja que un entrelazamiento similar también debería regir el plano de la ficción, la cual, imitando la realidad, nunca podría ser, ni totalmente monista, ni completamente nihilista. Si hubiera que identificar un texto concreto en el que se explore la relación existente entre nihilismo y monismo, sin duda el I-Ching destacaría entre los demás ${ }^{7}$. Este tratado ofrece:

a) por un lado un sucinto resumen de las limitadas posibilidades combinatorias existentes en un universo cerrado de relaciones causales que se epitomizan en un limitado listado de anagramas,

b) y por otro la posibilidad de la experimentación práctica y aleatoria para aquél que quiera anticipar qué será lo más probable que ocurra al llevar

6. Gasta (2011) resume las principales aproximaciones históricas al problema de la realidad y sus niveles en la novela: «In El pensamiento de Cervantes, Américo Castro suggests that Cervantes's conception of reality (ser versus parecer) in Don Quixote is inherently problematic and should be approached keeping in mind the author's unique form of perspectivism. Similarly, the socio-linguist Leo Spitzer acknowledged that a "linguistic perspectivism" anchors the novel such that a host of neologisms like the famous "baciyelmo" support equally valid but opposing views of the same object. These studies have been followed by research devoted to narrative point-of-view perspectivism: Manuel Durán discusses perspectivism as an expression of ambiguity and multiplication of narrative points of view» (145); «for E. C. Riley Don Quixote is marked by multiple versions of the same events; Juan Bautista Avalle-Arce asserts that truth depends on point of view» (9); «John J. Allen declares that the novel is "an exploration of the fertile pos- sibilities in the management and manipulation of point of view"» (130); «and James A. Parr counts as many as eleven different narrative voices in the novel, all providing their own divergent views» (57).

7. Para un estudio del I-Ching en relación con la creación de situaciones acausales y Jung ver Zabriskie (2005). 
a cabo una acción derivada de una decisión originada por un ser consciente, siempre vinculado a las combinaciones existentes entre las dadas en los ortogramas.

El entorno de los ortogramas es alterado a partir de la intervención del ser consciente, tras el acto de echarlos a su suerte; el aleatorio lanzamiento de los dados se combina con el planteamiento del ser consciente en sólo uno de los potencialmente causales anagramas.

Entender el modo en el que funciona el I-Ching ayuda notablemente a comprender el entrelazamiento existente entre monismo y nihilismo preeminentes. El I-Ching como metonimia del orden del cosmos informa sobre la relación entre una matriz limitada de posibilidades y la acción aleatoria en espacio-tiempo del ser consciente que se aproxima a este tratado buscando poder anticipar o responder ante acciones sobre las que tiene dudas con cada acto de consulta.

El I-Ching utilizado como oráculo ofrece situaciones en las que los ortogramas en potencia ponen en relación lo preeminente monista con lo preeminente nihilista, desequilibrando respectivamente alguno de sus principios para recombinarlos en el mismo instante, sin ser, ni completamente lo uno, ni completamente lo otro. Para que esta circunstancia se produzca es necesaria la consciencia equilibradora del Hombre.

\section{SYMPLOKÉ, VIDA, MUERTE Y VEROSIMILITUD CERVANTINA}

La comprensión y aceptación de la symploké de realidades monistas y nihilistas es esencial en el momento de la conclusión de la existencia de ciertos personajes del Quijote, alcanzándose tras ello un sentido único de verosimilitud. El autor del prólogo plantea casos de personajes imbuidos de trágicas revelaciones sobre el modo en el que la realidad opera, que se resuelven de maneras radicalmente distintas: por un lado, algunos no comprenden ni aceptan las leyes de la symploké. Grisóstomo y Anselmo son casos fatales por su incapacidad de afrontar el entrelazamiento que rige la realidad, basada exclusivamente en un entorno en donde todo está predominantemente interconectado (monismo) -la ficción de la alegre realidad de ser un pastor de ficción o de ser un creador de novellas hiperreales, de las cuales pueden llegar a formar parte-, ni en uno en el que nada está predominantemente relacionado con nada (nihilismo) - la cruda realidad de ser un joven rechazado por alguien «condenado a condenarle» o un marido engañado por su mejor amigo.

Por otro lado están aquellos personajes cuya comprensión y estoica aceptación del funcionamiento y entrelazamiento del funcionamiento dual de la realidad conduce al sereno abandono de la vida. Con el fin de Don Quijote y el renacimiento de Alonso Quijano la solución ejemplar al problema de dirimir la naturaleza profunda del dualismo que ordena la realidad se manifiesta 
abiertamente. El haber pertenecido al universo eminentemente monista -ser Don Quijote- no le es óbice para dejar de aceptar su pertenencia al preeminentemente nihilista -ser Alonso Quijano. A este último paso se abraza el protagonista siguiendo un orden moral, ser bueno, porque al fin y al cabo, su obra ha de finalizar ejemplarmente y respetando su libre albedrío como defiende el prólogo a la primera parte.

Las dispares conclusiones de las existencias propuestas, la naturaleza de las symplokés de la realidad, se ponen a prueba en la obra cervantina. Las consecuencias de la no aceptación de la naturaleza dual que rige la realidad, junto a la ética asociada a su asimilación estoica, se plantean dentro de un marco de entornos complementarios:

a) uno regido por leyes eminentemente monistas, de acciones interrelacionadas, como es el ámbito de la ficción, de Don Quijote, Grisóstomo y Anselmo,

b) el otro, eminentemente nihilista, es el que rige el universo manchego del resto de los personajes de ambas partes.

Dos protagonistas diferentes nos informan del cambio entre el orden de la realidad en la obra desde el de Don Quijote (eminentemente monista) hasta el de Alonso Quijano (eminentemente nihilista). La simulación de la ficción, espejo del universo real, es finita. Como tal, está en el origen del ser simulado su potencial capacidad de descubrir al simulador, en este caso Don Quijote a Alonso Quijano y viceversa. La limitada conexión de la posibilidad de poder haber vivido en una simulación finita conduce a resultados distintos dependiendo del estado del ser que se enfrente a esta realidad.

\section{a. Comprensión y no aceptación de la symploké de los órdenes de la realidad: Los casos de Grisóstomo y Anselmo}

En la obra cervantina se presentan dos casos de personajes en los que la transición entre compartir una realidad esencialmente monista y otra esencialmente nihilista se resuelve trágicamente. Grisóstomo y Anselmo rechazan su pertenencia a un entorno eminentemente nihilista, tras haber pertenecido circunstancialmente al preeminentemente monista de sus respectivas ficciones personales, optando por el abandono de la realidad en su conjunto mediante un cambio radical en sus existencias. Es el suicidio en el caso de Grisóstomo, el destierro y la vida de soldado con final trágico en el de Anselmo.

\section{Pastor de monismos}

El asunto del pastor Grisóstomo se extiende desde el capítulo doce al catorce de la primera parte del Quijote. La ficción bucólica es una de las posibles arquitecturas de la realidad en la que decide encerrarse este personaje, siendo su muerte un sacrificio ineludible para una fallida existencia en este ámbito. 
$\mathrm{Su}$ final es la culminación del proceso decepcionante de saber que nunca había dejado de ser parte de su vida antes de creerse pastor en un universo eminentemente nihilista del que creía haberse desligado, tras haber experimentado la realidad que ordena el simulado universo eminentemente monista de la ficción pastoril circunstancial y casualmente compartida con Marcela.

La historia de Grisóstomo y Marcela concluye con la muerte del primero, enamorado y no correspondido por la joven, creyendo como Don Quijote en relación a las novelas de caballerías, que lo que ocurre en las ficciones bucólicas, desmitificado en El coloquio de los perros por parte de Berganza en su diatriba contra los pastores-lobos, es aplicable a su propia realidad. Por ello se considera con el derecho de reclamar el amor de la bella joven y hasta de ser correspondido. Pero su trágica muerte quedará en segundo plano, tras la enorme credibilidad otorgada por los presentes y en especial Don Quijote, al discurso de la mujer acosada. La voz femenina de Marcela se eleva por encima de la muerte del falso pastor, diluyendo su trágica y sentimental aura. Un hecho irrefutable del final de las palabras de Marcela es que Grisóstomo muere a causa de errores nacidos de su sentido del orden de la realidad, no por aquellos originados en la natural sensualidad y belleza de la pastora de ficción. ¡Qué diferente es su muerte a la de Don Quijote, a pesar de que ambos personajes comparten el mismo error de interpretación existencial!

Grisóstomo elige como forma de vida no desvincularse nunca de un universo monista, de una ficción bucólica en la que todo está interrelacionado. $\mathrm{Si}$ alguien ama a alguien, la correspondencia es potencialmente posible, como ocurre en la mayor parte de las obras de ficción fijadas por el acuerdo entre autores y lectores, dentro del popular género literario al que se entrega el protagonista. La imposibilidad de distinguir la naturaleza del entrelazamiento de la realidad y de la ficción por parte de Grisóstomo le equipara a Don Quijote $^{8}$. Sin embargo, este último será capaz de regalar al lector la última gota de ejemplaridad de la historia en su reconocimiento y transformación al final de la trama. Por ello, mientras la actitud el primero es patética, la del segundo es más bien heroica.

8. La de Grisóstomo es una conclusión similar a la de uno de los protagonistas de la historia del filme Die Welle (La ola, de Dennis Gansel, 2011). Diferentes capas de fícción y realidad se acumulan en esta versión, basada en un hecho original acaecido en un instituto de Palo Alto, California en 1967, adaptado también a una serie televisiva de 1980 en la que basa la obra de Strasser y Morton (1981). El personaje de Tim Stoltefuss responde perfectamente al arquetipo trágico de Grisóstomo. Ninguno de los dos protagonistas se quiere separar de sus respectivas ficciones eminentemente monistas, el primero de la bucólica, el segundo de la autocrática, de las que otros personajes como Marcela o los compañeros de escuela de Tim Stoltefuss han sabido entrar y salir. Llegado el momento de la verdad y cuando la artificialidad del monismo en el que han vivido de prestado es aceptado por el resto, se quiebran todas sus expectativas de permanecer en su predecible realidad. Es entonces cuando ambos personajes deciden abandonar la vida antes que reincorporarse a una identidad pasada. Finalmente, el haber descubierto lo finito de la simulación presupone el rechazo y abandono del sentido del ser simulado. 


\section{El simulador simulado de Florencia}

El destino de Anselmo en El curioso impertinente es similar al de Grisóstomo, siendo ambos personajes y a la vez creadores de una ficción en la que se incluyen ellos mismos. En el caso de Grisóstomo, la ficción pastoril que le precede es compartida por otros, tras haber estado Marcela imbuida en ella. En el caso de Anselmo, la pretensión de encerrar a su mujer Camila y a su mejor amigo Lotario en un universo simulado en el contexto de un entretenimiento sublime sugiere, tanto el alcance, como los límites del libre albedrío. Anselmo es la experimentación del impertinente, parte de la historia de un experimento que también lo es fuera de tiempo y lugar. Una vez traspasada la frontera del matrimonio, el protagonista renuncia a una de sus reglas de oro, pretendiendo seguir manteniendo una amistad profunda con Lotario. Este desafío temporal pretende alargar el estado de armonía de la amistad anterior a la boda, materializado en su extremo con la proposición de Anselmo a Lotario de que intente seducir a su mujer. El precio que Anselmo paga por su osadía es que la ficción concluya con su mejor amigo cumpliendo con su cometido al pie de la letra. La ignominia mancha el territorio eminentemente monista de la ficción. Anselmo entonces ya no puede retornar al paraíso perdido eminentemente nihilista del comienzo de una obra, lo que confirma la imposibilidad ejemplar de armonizar matrimonio y amistad profunda. Ha creado un entorno eminentemente monista, pero se le ha escapado de las manos. Ante esta situación desaparecerá públicamente para morir al poco tiempo como soldado, intentando como Vidriera restituir por las armas el honor perdido en las «letras».

\section{b. Aceptación de la symploké de la realidad: Don Quijote, Alonso Quijano y viceversa}

El episodio de la muerte de Don Quijote se hace más comprensible en el marco de su asimilación y comprensión del sentido de la symploké que ordena la realidad. Al final de la obra, el universo de posibilidades de Don Quijote se reducirá a una sola, su propia muerte. Un aleatorio lanzamiento del dado en forma de sueño le conducirá a su desaparición y transformación definitiva en aras de su nueva identidad como Alonso Quijano. La ausencia de vida de Don Quijote podría ser virtual, pero al morir como Alonso Quijano la suerte confirma un retorno desde el universo eminentemente monista de las novelas de caballerías al entorno de singularidades de La Mancha. Al presentar dos realidades que responden a diferentes órdenes, la de ficción al universo preeminentemente monista y la histórica manchega, dominantemente nihilista de golpes, caídas y muertes físicas, la última acaba imperando. Tanto por ser aquella con la que el lector se identifica más, como por ser a la cual pertenece el mismo receptor junto al autor, en su común deseo de alcan- 
zar un final ejemplar para el protagonista de la obra que confirme lo anticipado en el prólogo. El propio hecho de leer cada letra, palabra o línea, tanto como el probar suerte con los ortogramas, son actos creativos y singulares en tiempo y espacio, como entrelazado está el holismo de posibilidades asociadas al eminente monismo en el género caballeresco.

La naturaleza de la symploké preponderante entre monismo y nihilismo ayuda a entender la entrelazada realidad presente en el Quijote, la cual se manifiesta en el contexto de una dinámica existencial a medio camino entre holismo y monismo, a partir de la singularidad de los personajes de Don Quijote y Alonso Quijano, protagonistas del último capítulo. Es éste es el único episodio, junto al primero de la primera parte del Quijote, en el que se ofrece tal duplicidad y cambio de identidad. El sueño que transforma y sirve de frontera entre realidades no es exclusivo del Quijote, ni siquiera de la obra de Cervantes, aunque existen ejemplos de sueños cervantinos transformadores de la identidad de los protagonistas en los que se presentan elementos necesarios para distinguir entre diferentes planos de la realidad que se aparecen a partir de la común relación entre los planos de la symploké.

El personaje de Don Quijote nace de un pensamiento alimentado anormalmente de novelas de caballerías y regido por una circunstancial interrelación entre la realidad monista, que ordena eminentemente el mundo caballeresco, y la predominantemente nihilista que impera en la Mancha. Esta bipolarización de posibilidades existenciales está sembrada de frecuentes vaivenes que concluyen con la transformación arquetípica del personaje al final de la obra. Ésta se produce tras un ritual sueño, común elemento de un umbral arquetípico entre dimensiones de la realidad, algo que se aprecia en otros casos cervantinos como son el descenso a Montesinos y las novelas ejemplares de El casamiento engañoso y El coloquio de los perros.

\section{El sueño en el descenso a Montesinos}

Don Quijote es «despertado» y apartado de una visión única en este episodio. El discurso que sigue a su salida de la cueva tiene como principal argumento el justificar lo vivido como realidad y no meramente como sueño, algo que ocurre de manera diferente que en el caso de El casamiento engañoso y El coloquio de los perros. La interconexión entre las dos historias, una más real que la otra, contribuye a reforzar la veracidad de la primera, siendo el mundo de las vibraciones, inmaterial y holístico, materia de los sueños. El universo de lo material y nihilista es del ámbito de los seres animados, los cuales bien ofrecen su testimonio personal (Don Quijote) o su interpretación sobre lo escuchado (Cañizares). Un sueño último hace que Don Quijote retome su estado original de Alonso Quijano, de un modo similar al momento de su salida de la cueva de Montesinos. En ambos casos, el mismo protagonista se desdobla en dos realidades entrelazadas; a) aquella eminentemente holística, naturaleza de la imaginación de la mente (lo ocurrido dentro de la cueva), de la obra de ficción (novela de caballerías) o materia de los sueños (El casa- 
miento engañoso y El coloquio de los perros) y b) aquella predominantemente nihilista mediante la cual se intenta explicar lo ocurrido, estableciéndose vínculos con una realidad que sólo el que la ha vivido puede confirmar que pertenece al mundo de lo casual; Don Quijote en ambos casos y Berganza en El casamiento engañoso y El coloquio de los perros.

\section{El sueño en El casamiento engañoso y El coloquio de los perros}

A partir de los datos objetivos aportados en El coloquio de los perros el lector se informa del sueño de un hombre afectado por sífilis sobre una conversación entre dos perros. Ambos dialogarán platónicamente sobre el asunto general de la diferencia entre los principios de la virtud y el adulterio de la misma, ilustrados por numerosos ejemplos. Carniceros que se dejan robar carne, pastores que asesinan ovejas en la oscuridad culpando a los lobos, poetas y comediantes sin talento pero con pretensiones, entre otros. La confirmación de que también los lectores podemos estar soñando tiene que ver con el hecho de que el final de la historia coincide con el despertar del protagonista soñador.

\section{De la symploké platónica a la cervantina}

Tras haber estado voluntariamente encerrado en el universo particularmente monista de las novelas de caballerías y habiéndose enfrentado al nihilismo que rige el entorno de La Mancha, el protagonista decide abandonar pacífica y públicamente la preeminentemente monista identidad de Don Quijote, abrazando la realidad eminentemente nihilista de Alonso Quijano. Con esta acción no sólo se implica su reconocimiento de la existencia de ambas, sino también se hace público su deseo de no querer ser recordado como grandioso loco, sino como buen hidalgo. Siendo este acto definitivo e irreversible también servirá, tanto de contraejemplo a los casos de Grisóstomo y Anselmo, como para ilustrar ejemplarmente el modo en el que opera la realidad para cualquiera consciente del dual plano que la ordena.

En esta conclusión, elegida para las aventuras de Don Quijote, el protagonista ha aceptado la realidad acogida a la symploké o entrelazamiento basado en una lógica de los hechos que no es enteramente monista y a que su existencia no concluye al tiempo de la ficción a la que pertenece. Pero tampoco es enteramente nihilista: la muerte de Alonso Quijano no es completamente intranscendente, al reconocerse como parte esencial de la creación del propio personaje de Don Quijote. ¿Qué mejor ejemplo de la materialización de la symploké que esta paradoja existencial de dos seres conscientes, capaces de crearse y morirse a voluntad propia?

La vida de Alonso Quijano culmina tras el capítulo final de la segunda parte del Quijote. El Don Quijote recordado por los lectores es consecuencia de la aceptación final del protagonista de la symploké o entrelazamiento de entornos preeminentemente monistas y nihilistas. La locura o enfermedad que 
ha acompañado a Don Quijote se neutraliza al ser el personaje autoconsciente de sus limitaciones en la participación de los órdenes que rigen la realidad del universo.

En los dos volúmenes del Quijote se presenta, tanto el orden de la historia (eminentemente nihilista), como el de la ficción (eminentemente monista), siendo este último del cual los lectores Sansón Carrasco y los duques intentarán apropiarse en la segunda parte, a partir de su conocimiento previo de las acciones de Sancho y Don Quijote en la primera parte. La muerte del protagonista separará ejemplarmente ambas partes, en un esfuerzo por distinguir claramente el final del camino del personaje de ficción caballeresca del de la historia «normal» del hidalgo de la Mancha. Con ello se aceptará la concentración de toda la acción en la culminación de la vida de un personaje histórico-nihilista (Alonso Quijano), el cual se hace más verosímil a partir de la negación del su ser de ficción-monista (Don Quijote). Es también un remate de los finales unidos de ambos tomos de aventuras, los cuales ya no dan para más, porque tampoco es posible prolongar la verosímil existencia del protagonista. La conclusión de la segunda parte culmina la existencia preeminentemente monista de Don Quijote entrelazada a la preeminentemente nihilista de Alonso Quijano, que se separarán armónica y ejemplarmente. Como se había defendido tanto en el prólogo como en los primeros capítulos de la segunda parte del Quijote, la fama acompaña a la ficción ejemplar, rematando la ética del buen morir una existencia indigna de ser imitada.

En el capítulo que culmina la segunda parte del Quijote confluyen las líneas argumentales que desvelan cómo acaba la primera. Terminarán las vidas del propio Don Quijote y la de Alonso Quijano tal y como desea este último. Este proceso comienza significativamente con una intervención del autor, informando de que Don Quijote, por «disposición del cielo», se aproxima a su final. Cobra así mayor sentido el retorno a la aldea natal de Alonso Quijano. Éste ha de cumplir la necesidad de confirmar el final de la primera parte del Quijote en un discurso cargado de seriedad; el oscuro humor se ha ido diluyendo, siendo sustituido por lo más hondo y transcendente de la historia:

Como las cosas humanas no sean eternas, yendo siempre en declinación de sus principios hasta llegar a su último fin, especialmente las vidas de los hombres, y como la de Don Quijote no tuviese privilegio del cielo para detener el curso de la suya, llegó su fin y acabamiento cuando él menos lo pensaba; porque, o ya fuese de la melancolía que le causaba el verse vencido, o ya por la disposición del cielo, que así lo ordenaba, se le arraigó una calentura que le tuvo seis días en la cama, en los cuales fue visitado muchas veces del cura, del bachiller y del barbero, sus amigos, sin quitársele de la cabecera Sancho Panza, su buen escudero (II, 74, 1099).

La muerte consecutiva de Don Quijote y Alonso Quijano, por este orden, se produce tras el diagnóstico del médico, el cual asegura que se debe a «melancolías y desabrimientos» (II, 74, 1099). Es decir, a un trastorno emocional asociado a una pena profunda que amenaza un contagio de la propia obra 
narrativa hasta el ánimo de un lector plenamente implicado al final de la lectura. Tras despertarse al día siguiente, Alonso Quijano «el Bueno» se reafirmará en los principios que rigen la realidad interior pública en su aldea. Mientras Don Quijote había nacido originalmente de alguien asociado a la bondad, se conduce ahora al lector de nuevo hacia el origen, al Alonso Quijano residente en La Mancha. El hidalgo venido a menos confirma que su juicio está «libre y claro, sin las sombras caliginosas de la ignorancia, que sobre él me pusieron mi amarga y continua leyenda de los detestables libros de las caballerías» (II, 74, 1100). Su recuperación de una razón perdida, al igual que ocurrió en la bajada a Montesinos, se lleva a cabo tras un sueño que ha abierto una puerta hacia la aceptación de otra realidad. La identidad escondida en el cuerpo del Don Quijote es recuperada a partir de la memoria de Alonso Quijano.

Al final de su vida, el protagonista de la novela ha regresado para unirse al autor del prólogo en su anti-utópico propósito de combatir las novelas de caballerías. Cumplida la desaparición de Don Quijote en la novela, le toca entonces hacerlo a Alonso Quijano, el cual ruega confesión y hace testamento (II, 74, 1100). La acción evoca los primeros capítulos de la segunda parte, específicamente los diálogos sobre la fama entre Sancho, Don Quijote y Sansón Carrasco. En contraste, con la transformación de Don Quijote en Alonso Quijano, la búsqueda de celebridad y reconocimiento se fundirá al anhelo de transcender la vida mediante valores cristianos. El hidalgo quiere morir y ser recordado como bueno y en paz, más que por su exclusiva asociación con Don Quijote. Alonso Quijano ha renacido del sueño alegórico de la vida de Don Quijote la noche anterior a su transformación. La heroica aceptación del destino ilumina, tanto a Don Quijote, como a Alonso Quijano, confirmando su renacimiento para la posteridad:

Dadme albricias, buenos señores, de que ya yo no soy Don Quijote de la Mancha, sino Alonso Quijano, a quien mis costumbres me dieron renombre de Bueno. Ya soy enemigo de Amadís de Gaula y de toda la infinita caterva de su linaje, ya me son odiosas todas las historias profanas del andante caballería, ya conozco mi necedad y el peligro en que me pusieron haberlas leído, ya, por misericordia de Dios, escarmentando en cabeza propia, las abomino (II, 74, 1100-01).

Alonso Quijano confirma su alejamiento de Don Quijote y simultáneamente se distancia de la locura, acercándose a la bondad católica. Instantes antes de su muerte prevalece su denodado esfuerzo de renacer pública y moralmente como cristiano (II, 74, 1101) $)^{9}$.

9. Según Torres Antoñanzas (1998: 401): «Su muerte es la renuncia a unos espurios ideales de auto-divinización tras operarse una "iluminación" de la razón que le permite recuperar definitivamente su condición de hombre de aldea». Murillo (1988: 257) defiende la supervivencia de Don Quijote por encima de la memoria de Alonso Quijano: «The narrator concedes to his character both the triumph of his true self over error and madness and the triumph of his fictional self over humiliation and ridicule. The narrator disposes of his hero much as a 'Christ of Fiction'». 
El protagonista se distancia de cualquier sentido de burla, separando de su imagen de la de un loco. Siguiendo con este tono renovadamente serio, Alonso Quijano se disculpará ante su compañero de aventuras, confirmándole la falsedad de sus creencias: «Perdóname, amigo, de la ocasión que te he dado de parecer loco como yo, haciéndote caer en el error en que yo he caído, de que hubo y hay caballeros andantes en el mundo» (II, 74, 1102). Sancho por su parte reafirmará que la melancolía ha acabado con la vida de Don Quijote, entendiendo siempre que él es el que muere, lo que confirmará al seguir tratándole como señor (II, 74, 1102-03). El renacimiento previo a la muerte física se confirmará burocráticamente:

Viendo lo cual el cura, pidió al escribano le diese por testimonio como Alonso Quijano el Bueno, llamado comúnmente Don Quijote de la Mancha, había pasado de esta presente vida y muerto naturalmente; y que el tal testimonio pedía para quitar la ocasión de algún otro autor que Cide Hamete Benengeli le resucitase falsamente, y hiciese inacabables historias de sus hazañas (II, 74, 1104).

Llamativamente, el epitafio elaborado por Sansón Carrasco apunta al necesario final de ambas existencias en un «morir cuerdo y vivir loco» (II, 74, 1105), lo cual se unirá a la percepción de la primera parte, contra la cual combate Don Quijote en la segunda.

Muere el Don Quijote de la primera parte, el cual había transcendido notablemente entre su público, tanto en el ámbito de la ficción, como en el histórico, durante diez años. Lo hace también el protagonista de su segunda parte, renaciendo en un Alonso Quijano que abandona este mundo tras ser afectado por una profunda melancolía ${ }^{10}$. Cumpliendo con el prólogo a la primera parte, las pautas para combatir las novelas de caballerías se han compartido con el lector, confiando en que éste haya sido capaz de entender cómo funcionan para su provecho. La obra de ficción resultante ha contribuido a advertir al receptor de esta historia sobre sus diferentes peligros, entre los que se encuentra un desequilibrio asociado a no poder aceptar o comprender la symploké del orden de la realidad.

La verosimilitud cervantina se ha de entender como un acto de generosidad desde el autor hacia sus lectores, informados de que las ficciones pueden funcionar como remedo de la realidad en las imperfectas mentes humanas. Como el pensamiento que invade El libro de buen amor de Juan Ruiz, conocer y experimentar lo «malo» ayuda a valorar lo «bueno».

En la primera parte, cegado por su materialismo, Sancho no querrá dudar de que la Micomicona exista. El rústico queda vinculado a las novelas de ca-

10. Para un resumen sobre los debates principales acerca del final del Quijote ver Lo Ré (1989) y Schmidt (2000). Llama especialmente la atención la defensa del último autor de que Alonso Quijano es consciente de su acto de interpretación en su transformación arquetípica de Alonso Quijano a don Quijote (Schmidt: 123). Para un estudio reciente sobre la muerte en de don Quijote utilizando el concepto de mito como corrupción histórica en el Quijote ver Pérez de León (2014). 
ballerías llevadas a la realidad, narcotizado por su propio interés material, sobre todo tras querer creerse el simulacro ordenado en torno a su impersonificación como gobernador en casa de los duques. A pesar de los atropellos que ha sufrido acabará pidiendo a Don Quijote que continúe con sus aventuras para así poder seguir dando sentido a su vida. La muerte de Alonso Quijano parece dejar a un Sancho dispuesto a seguir las hazañas de cualquier otro señor, a ser posible aquejado de una melancolía que le obligue a llevarlas a la práctica.

La fama adquirida por el Alonso Quijano retornado en Don Quijote obliga al protagonista, empujado por Sansón Carrasco y otros aficionados a sus aventuras, a volver para demostrar que todavía es un «superhéroe» de ficción al principio de la segunda parte. Una vez más, el contagio entre los admiradores y seguidores del hidalgo confirma ejemplarmente que la ficción inhibe peligrosamente de la realidad. El cura, el barbero, Dorotea y Sansón Carrasco, con la excusa de devolver a Quijano a su aldea, se asociarán al Don Quijote famoso. Al hacerlo transcienden ficción e historia al ser parte de ambas, como bien saben también los duques.

En esta obra que ahora concluye el autor entrega al lector el secreto de la realidad entrelazada, de la dinámica de la inseparabilidad de las dos áreas opuestas del diagrama del ying-yang. Ambas mitades aparentan comenzar en un punto para estar eternamente circulando en equilibrio. El secreto de su relación es su symploké. Ninguna por sí sola explica el funcionamiento del todo, el cual responde a la naturaleza de su misterioso entrelazamiento. Del mismo modo que la existencia eminentemente monista de Don Quijote es reconocida por Alonso Quijano, el cual aceptará que no es hegemónica, la dinámica eminentemente nihilista del Quijote es recuperada irreflexivamente por Alonso Quijano al final de su existencia. El hidalgo ha aprendido que no es Don Quijote, pero a pesar de sus esfuerzos, tras el breve intervalo que precede a su desaparición física, la fama que habrá acumulado como personaje que se creía de fícción permanecerá junto a la que le precede como buen cristiano. Ni exclusivamente uno, ni lo otro, sino un simploké de ambas alimentan la cordura que rige la existencia humana.

El lector ha sido capaz de apreciar desde su privilegiada posición, tanto la dinámica monista como la nihilista de la realidad. La fuerza de la perspectiva de observación del receptor del Quijote reside en su capacidad de percibir de qué modo se articula la symploké que une ambas posibilidades. La superposición de la entretejida materia de la realidad es decisiva para que el desocupado lector asocie su voluntad a las palabras del libro cervantino, siendo el código de la novela de caballería que rechaza Alonso Quijano sustituido temporalmente por el de los cristianos buenos.

\section{Conclusión: La naturaleza del entrelazamiento de simulados y simuladores} cervantinos

La validez de la fórmula de la symploké platónica, entrelazamiento entre «no todo monismo» $\mathrm{y}$ «no todo nihilismo» para entender la alternancia existente 
entre realidades existenciales para varios de los protagonistas del Quijote se ha puesto en evidencia a través de casos de personajes ejemplarmente opuestos. Por un lado el no deseado del suicidio del pastor Grisóstomo, estudiado en el contexto de un caso similar, el de la muerte de Anselmo en El curioso impertinente. Por otro, el ejemplar del final arquetípico de Don Quijote y su renacimiento en la persona Alonso Quijano. El sueño que regenera a Alonso Quijano está también presente en la cueva de Montesinos y El coloquio de los perros, como recursos arquetípicos de transición entre realidades.

La tragedia derivada de cuestionar el principio de la symploké platónica ayuda a explicar el apego, la identificación y la naturaleza del entrelazamiento en los ejemplos estudiados, los cuales alternan entre realidades preeminentemente monistas y nihilistas. Mientras el estado «normal» y deseable sería el de ser capaz de vivir entendiendo que el ser humano percibe la realidad filtrada por un dinámico entrelazamiento entre un universo que ni es enteramente monista, ni completamente nihilista, éste no es siempre el caso, lo cual puede conducir a consecuencias no deseables.

En la historia de Grisóstomo, el resultado de su apego al universo de ficción monista concluye en su renuncia a vivir en un mundo nihilista. El protagonista permanecerá en la memoria colectiva como un infame-famoso que pretendió haber vivido para amar bucólicamente. Sin embargo, tras escuchar el discurso de una Marcela distanciada del monismo de ficción, Grisóstomo confirma ser un personaje lleno de patetismo al estar equivocado a causa de un error existencial similar al de Anselmo en El curioso impertinente. Por otro lado, el renacimiento de Alonso Quijano tras el sueño en el que desaparece Don Quijote presenta otra vía posible, la de la renuncia pública y heroica de la identidad inventada y suplantada en el camino para alejar a los lectores del primigenio error perceptivo asociado al ser humano, reconociéndose así nuestra imperativa tendencia a identificarnos con una realidad exclusivamente monista.

Descubrir a los simuladores no es siempre una tarea fácil ni carente de peligro. Grisóstomo y Anselmo acabarán comprobando que lo son ellos mismos, realidad insoportable que les conduce a su autodestrucción. Tras haberse aferrado a la simulación que han superpuesto a sus existencias, al desaparecer ésta tampoco tiene sentido que pervivan. Muy al contrario, cuando se ausenta voluntariamente el caballero de ficción, renacerá ejemplarmente Alonso Quijano, confirmándose el primigenio mensaje del prólogo a la primera parte.

Es inevitable que el ser simulado preeminentemente nihilista que sobrevive en un entorno finito intente suplementar este descompensado y nunca completo orden de la realidad con uno eminentemente monista, su natural opuesto. El arte de la ficción es preeminentemente monista y aparentemente finito, aunque menos limitado que la imaginación contenida en el cerebro del artista simulador. Como pequeño mundo, el Hombre simula por naturaleza, siendo a su vez ser parte de una simulación en su tendencia a equilibrar el orden cósmico en su constante contribución a la creación del presente. Ya que 


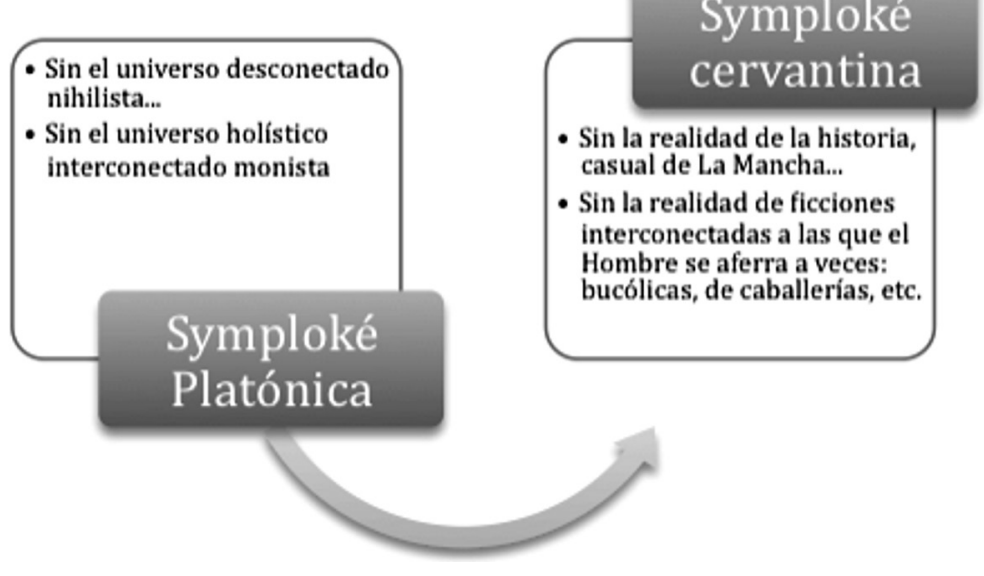

su materia recóndita esconde cargas de significado primigenio compartidas con el resto del universo, su finitud ha de tender a equilibrar lo infinito del apetito imaginativo.

Al igual que la existencia, la ficción cervantina se basa en un permanente diálogo de opuestos, equilibrios y desequilibrios expuestos y hasta aderezados de libre albedrío, de los cuales seres simuladores y simulados participan, decidiendo y organizando el modo en el que las symplokés de sus realidades se ordenan, delimitando así su propia participación en el orden de la realidad. El pequeño mundo de Alonso Quijano ha simulado a Don Quijote, el cual ha expandido su preeminentemente monista identidad en el preeminentemente nihilista vacío de la Mancha, simulando en el proceso la dinámica equilibrante de la symploké del propio cosmos. En su último suspiro Alonso Quijano ha sabido escapar del orden monista que le había esclavizado recientemente debido a la atracción que ejercía hacia aquellos capaces de simular escenarios adecuados a su identidad como caballero (Sansón Carrasco y los duques principalmente), retornando a su estado anterior preeminentemente nihilista, no sin antes querer probar a ser un pastor como Grisóstomo. Con ello no sólo confirma a sus lectores que lo simulado siempre puede acabar identificando a su simulador, sino que este último es parte esencial y generadora de ambos estados.

\section{BIBLIOGRAFÍA CITADA}

Baudrillard, Jean (1983). Simulations. New York: Semiotext(e).

Beane, Silas R., Davoudi, Zohreh y Savage, Martin J. (2012). «Constraints on the Universe as a Numerical Simulation». Accesible en <arxiv.org/abs/1210.1847> (27.11.2014).

Bostrom, Nick (2003). «Are We Living in a Computer Simulation?», The Philosophical Quarterly. 53.211, pp. 243-255. 
Bueno, Gustavo (1972). Ensayos Materialistas. Madrid: Taurus.

Bueno, Gustavo (2005a). «Don Quixote, Mirror of the Spanish Nation». Fundación Gustavo Bueno, Oviedo. Accesible en <http://www.fgbueno.es/ing/gbm/2005quix.htm> (27.11.2014).

Bueno, Gustavo (2005b). «Sobre el análisis filosófico del Quijote», El Catoblepas. 46.2, p. 2.

Burningham, Bruce R. (2008). Tilting Cervantes. Baroque Reflections on Postmodern Culture. Nashville: Vanderbilt UP.

Cervantes Saavedra, Miguel de (2004). Don Quijote de la Mancha. Madrid: Alfaguara.

García, Martha (2011). «Ciencia y conciencia teológica en Cervantes», Cervantes. 31.1, pp. 147-158.

Gasta, Chad (2011). «Cervantes's Theory of Relativity in Don Quixote», Bulletin of the Cervantes Society of America. 31.1, pp. 51-82.

Hidalgo Tuñón, Alberto (2006). «El conflicto de los mundos en El Quijote», en Bases y claves histórico-filosófico-políticas en el Quijote. Oviedo: Sociedad Asturiana de Filosofía-Ediciones Eikasía, pp. 69-104.

Jung, Carl (intro.)(1967). The I Ching or Book of Changes. Wilhem, Richard (ed.). Princeton UP.

Lo Ré, Anthony G. (1989). «The Three Deaths of Don Quixote: Comments in Favor of the Romantic Approach», Cervantes. 9, pp. 21-41.

Maestro, Jesús (2009). Crítica de los géneros literarios en el Quijote. Vigo: Academia del Hispanismo.

Maestro, Jesús (2006). La academia contra Babel: postulados fundamentales del materialismo filosófico como teoría literaria contemporánea. Vilagarcía de Arousa-Pontevedra: Mirabel Editorial.

Murillo, Luis A. (1988). A critical introduction to Don Quixote. New York: Peter Lang.

Pérez De León, Vicente (2014). «Mito y corrupción histórica en el final del Quijote». Anuario de estudios cervantinos, 10, pp. 141-54.

Pérez De León, Vicente (2015). «Sobre fama, infamia y la serpiente Ouróboros en la obra cervantina», en María Fernández Ferreiro (ed.), Actas VIII-CINDAC: Actas del VIII Congreso Internacional de la Asociación de Cervantistas. Alcalá de Henares: Centro de Estudios Cervantinos (en prensa).

Platón (1992). Diálogos V: Parménides, Teeteto, Sofista, Político. Madrid: Gredos.

Ramírez, Álvaro (2005). «Don Quijote and the Age of Simulacra», Hispania. 88.1, pp. 8290.

Rico, Francisco (2005). El pequeño mundo del hombre: varia fortuna de una idea en la cultura española. Barcelona: Destino.

Schmidt, Rachel (2000). «The Performance and Hermeneutics of Death in the Last Chapter of Don Quijote», Cervantes. 20.2, pp. 101-126.

Strasser, Todd y Morton, Rhue (1981). The Wave. New York: Dell.

Torres Antoñanzas, Fernando (1998). Don Quijote y el absoluto: algunos aspectos teológicos de la obra de Cervantes. Salamanca: Universidad Pontificia de Salamanca. Bibliotheca Salmanticensis, 199.

Wilhem, Richard (ed.), Carl Jung (intro.) (1967). The I Ching or Book of Changes. Princeton: Princeton UP.

Zabriskie, Beverley (2005). «Synchronicity and the I Ching: Jung, Pauli, and the Chinese Woman», Journal of Analytical Psychology. 50 (2), pp. 223-235. 


\title{
Resumen
}

Una de las claves de la realidad que ordena el universo reside en comprender la naturaleza del entrelazamiento de la dualidad que lo rige, nunca completamente monista, ni tampoco totalmente nihilista, según el principio de la symploké platónica (El sofista, 1992: 251, 255). La validez del entrelazamiento entre «no todo monismo» y «no todo nihilismo» se utilizará como herramienta lógica para entender la postura existencial de varios de los personajes del Quijote que protagonizan casos de raras y autoconsicentes conclusiones a sus propias existencias. Por un lado está la no deseada del suicidio del pastor Grisóstomo y su desesperación por Marcela, estudiado en el contexto del caso similar de la muerte de Anselmo en El curioso impertinente. Por otro está la ejemplar y reflexiva muerte arquetípica de Don Quijote y su renacimiento en Alonso Quijano. En conclusión, la identificación de la tragedia ontológica derivada de no comprender o no poder cuestionar el principio de la symploké platónica ayuda explicar el apego, la identificación y la naturaleza del entrelazamiento entre los personajes cervantinos estudiados en relación a su autoconsciencia de seres creativos incluidos, voluntariamente o no tanto, en los ámbitos de sus simuladas realidades.

Palabras clave: Cervantes; symploke; Don Quijote; El curioso impertinente; Grisóstomo; El sofista; Platón; Gustavo Bueno.

\section{Title: Simulating and Simulated Characters, Entangled in Don Quixote}

\begin{abstract}
One of the keys for understanding the ruling universe is the nature of the interconnected duality that governs it. It is neither completely monistic, neither absolutely nihilistic, according to the principle of the Platonic symploke (the Sophist 251, 255). The validity of the entanglement between "not everything are monisms" and the fact that reality is not completely "nihilist" will be used as a logic tool to understand the alternation in the understanding of the conclusions of the existences of several of the protagonists of the Quixote. On the one hand, it is the strange case of the suicidal shepherd Grisóstomo, in desperation for his loved Marcela, which is studied in the context of a similar case, the death of Anselmo in The Tale of Ill-advised Curiosity. On the other hand it is the case of the exemplary archetypical death of Don Quixote and his revival in Alonso Quijano "the good", which presents a similar case of (mis)understanding of the symploke principle. In conclusion, the ontological tragedy arising from not understanding or questioning the Platonic principle of the symploke will contribute to explain the attachment, identification, and nature of the entanglement between reality and fiction in selected cervantine characters. This will be achieved by focusing in both their self-awareness as creative beings and their more or less voluntary inclusion in, or exclusion from, their own simulated realities.
\end{abstract}

Key words: Cervantes; symploke; Don Quixote; Tale of Ill-Advised Curiosity; Grisóstomo; The Sophist; Plato; Gustavo Bueno. 